\title{
Understanding Smoke Exposure Results: Pinot noir Baseline Concentrations of Smoke Impact Markers across Five Vintages
}

Caroline P. Merrell, ${ }^{1}$ Torey J. Arvik, ${ }^{1}$ and Ron C. Runnebaum ${ }^{2,3 *}$

Cite this article: Merrell CP, Arvik TJ and Runnebaum RC. 2021. Understanding smoke exposure results: Pinot noir baseline concentrations of smoke impact markers across five vintages. Catalyst 5:4-11.

1Jackson Family Wines, 27000 Ramal Road, Sonoma, CA 95456; ${ }^{2}$ Department of Viticulture \& Enology, University of California, Davis, CA 95616; and ${ }^{3}$ Department of Chemical Engineering, University of California, Davis, CA 95616.

${ }^{*}$ Corresponding author (rcrunnebaum@ucdavis.edu)

Supplemental data is freely available with this article.

Manuscript submitted Aug 2020, revised Dec 2020, accepted Dec 2020

Copyright $\odot 2021$ by the American Society for Enology and Viticulture. All rights reserved.

By downloading and/or receiving this article, you agree to the Disclaimer of Warranties and Liability. The full statement of the Disclaimers is available at https://www.asevcatalyst.org/ content/proprietary-rights-noticecatalyst. If you do not agree to the Disclaimers, do not download and/ or accept this article.

doi: $10.5344 /$ catalyst.2020.20007

\section{Summary}

Goals: With increased wildfires in recent years, winemakers must be able to interpret analyses of smoke-related marker compounds to determine whether smoke intrusion has affected their wines. The goal of this study was to examine naturally-occurring, baseline levels of smoke exposure marker compounds in un-oaked Pinot noir to enable winemakers to better understand smoke exposure results. This study also sought to understand how baseline concentrations of smoke marker compounds change from year to year.

\section{Key Findings:}

- Pinot noir wines from California and Oregon had detectable baseline levels of free and bound marker compounds, including guaiacol, 4-methylguaiacol, 4 -ethylphenol, and $m-, p$-, and $o$-cresol. In 2019, the baseline free guaiacol concentration ranged from 1.2 to $2.3 \mu \mathrm{g} / \mathrm{L}$, while total (free and bound) guaiacol ranged from 6.4 to $12.0 \mu \mathrm{g} / \mathrm{L}$.

- The concentration of free guaiacol was greater in older vintages, while total guaiacol did not change much from year to year.

- The ratio of free to total guaiacol approached 1:2 after five years, suggesting baseline guaiacol may approach an equal ratio of free to bound over time.

Impact and Significance: While baseline levels identified here were low, winemakers should become familiar with the baseline concentrations in their wines to better understand risk during smoke-impacted vintages. With increased analysis of non-smoke-impacted, baseline samples, it may be possible to create a variety-specific risk matrix for smoke exposure. Additionally, as wines age, free volatile smoke marker compounds may increase due to normal changes to baseline compounds and may not always represent smoke-related glycosides releasing free volatiles.

Key words: analysis, aroma, guaiacol, Pinot noir, smoke exposure

\section{Overview}

Wildfire smoke has caused concern for wine quality around the world in the last two decades. As fires burn, volatile phenols are generated from the breakdown of lignin. Depending on the wood source, different types of volatile phenols are present in the smoke. ${ }^{1}$ These volatile phenols are then taken up by the plant, either directly through the fruit, or through translocation from leaves to fruit. ${ }^{2}$ Although multiple compounds are responsible for smoke aroma, guaiacol and 4-methylguaiacol are often used as key exposure markers because they are typically found in the highest quantities in smoke-exposed grapes and wines. ${ }^{3}$ Other compound classes implicated in smoke exposure aroma include syringyls (syringols), $p$-hydroxy-phenyls (phenols and cresols), and guaiacyls (guaiacols and eugenol). ${ }^{1}$ Baseline concentrations of these compounds in different wine varietals must be established to better understand changes attributed to smoke exposure during smoke-impacted vintages.

When volatile phenolics are taken up by the plant, they bind to sugar molecules to minimize the toxic effect on the plant. ${ }^{3,4}$ Current research examines 
which glycoconjugates form and how these compounds change over time during winemaking. ${ }^{5,6}$ However, because many compounds are present, this approach can be challenging for commercial laboratories to use as a screening tool for routine analysis. Acid or enzyme hydrolysis is used to estimate the concentrations of this group of compounds by releasing them into their free volatile form. ${ }^{3}$ Because sample analysis by acid or enzyme hydrolysis measures both initially free volatiles and volatile compounds released through the hydrolysis process, the protocol estimates the total pool of smoke phenolics present in a wine. While there are drawbacks to both acid and enzyme hydrolysis, including the formation of artifacts, acid hydrolysis is more reflective of grape and wine aroma than enzyme hydrolysis. ${ }^{7}$

Free volatile phenols are primarily responsible for smoke taint aroma and flavor, ${ }^{8}$ while glycosylated compounds contribute to smoke flavor and aftertaste. ${ }^{2,9}$ One sensory study reported the strongest smoke flavor in wines spiked with both free volatiles and glycosylated smoke-related compounds. ${ }^{9}$ Bound compounds may also hydrolyze to release their free volatile form during wine aging, making smoke aroma worse over time. ${ }^{10}$ This temporal change in free volatile phenolics has been most significantly noted regarding mitigation efforts, such as when wines are treated with reverse osmosis filtration, but smoke aroma returns over time. ${ }^{11}$ Due to the overall sensory impact of both free and bound compounds, it is important to measure both fractions to assess both the immediate smoke impact and the potential long-term risk.

Additionally, it is important to be familiar with baseline concentrations of both free and bound compounds to properly understand risk. Free and bound guaiacol were identified in non-smoked Merlot, Cabernet Sauvignon, Syrah, Tempranillo, Grenache, and Viognier. ${ }^{3,12,13,14,15}$ Many currently published baseline concentrations are from control wines in smoke exposure research. For example, a non-smoked Merlot wine had $4 \mu \mathrm{g} / \mathrm{L}$ guaiacol and trace levels $(<1 \mu \mathrm{g} / \mathrm{L})$ of 4 -ethylguaiacol, 4-ethylphenol, and eugenol. ${ }^{1,3}$ While these concentrations are often many orders of magnitude lower than those reported for smoked fruit and wines, a commercial lab reported that red wines with free guaiacol concentrations over $6 \mu \mathrm{g} / \mathrm{L}$ led to smoky wines; ${ }^{13}$ a limitation of this report is that it lacks a controlled sensory evaluation and the rigor of peer review. With such a narrow margin between normal and potentially smoke-impacted results, winemakers will be better prepared to assess risk if they know the typical baseline concentrations in their own wines.
To date, baseline concentrations of smoke volatile phenols are not widely available. Researchers at the Australian Wine Research Institute have conducted an intensive baseline survey, but this data has not yet been published. ${ }^{16}$ Additionally, there is limited understanding of the impact of growing conditions and site on the level of baseline concentrations. This study examines baseline concentrations of common smoke exposure marker compounds in Pinot noir wines from 15 different vineyard sites in California and Oregon. This study also compares concentrations of these compounds in wines at various stages of aging, so that winemakers can better interpret the relative impacts on their wines at any stage of maturation and therefore assess general risk when fires erupt in their winegrowing regions.

\section{Major Observations and Interpretations}

Pinot noir wines produced over five vintages (2015 to 2019) from California and Oregon were examined in February 2020 for volatile smoke compounds, including guaiacol, 4-methylguaiacol, 4-ethylguaiacol, 4-ethylphenol, and $m-, o-$, and $p$-cresol. Thirteen vineyard sites were analyzed in California and two were analyzed in Oregon (Figure 1). Over those five vintages, only one wine from 2018 was excluded due to potential environmental smoke impact as a result of its elevation $(\sim 500 \mathrm{~m})$, even though the smoke would have drifted more than $150 \mathrm{~km}$. While there were other fires in California and Oregon between 2015 and 2019, vineyards were either not impacted due to their location or harvested prior to smoke impact (Supplemental Table 1). In all years, concentrations of both free and total volatile phenolic compounds were measured. For clarity, we will use the term "total" to refer to the concentration after acid hydrolysis. Additionally, in this study $p$ - and $m$-cresol both showed loss of peak resolution after acid hydrolysis and were therefore only included in the analysis of free volatiles.

Pinot noir wines from various regions in California and the Willamette Valley of Oregon had detectable baseline levels of all measured smoke volatile phenols except 4-ethylguaiacol (Table 1). The concentration of all free volatile phenols was relatively low. In wines from the 2019 vintage, free guaiacol ranged from 1.2 to 2.3 $\mu \mathrm{g} / \mathrm{L}$ approximately three months after harvest (Figure 2). There was a similar range in cresol isomers by site, with a minimum of $0.6 \mu \mathrm{g} / \mathrm{L}$ in $m$-cresol and a maximum of $2.8 \mu \mathrm{g} / \mathrm{L}$ in $p$-cresol (Figure 2).

Free guaiacol increased significantly from more recent to older vintages (Table 1). This baseline increase in guaiacol is important to note, as winemakers who track 
wines over time may misinterpret the result as smoke glycosides being released into their free form. Other free volatile phenolic compounds either increased only slightly over time or remained constant. This result is consistent with previous research, which also saw increased smoke marker volatiles during bottle aging of wines not exposed to smoke. ${ }^{15}$

Neither vineyard location (American Viticultural Area [AVA]) nor rootstock significantly affected the concentration of smoke marker compounds. In this survey, only two to three vineyards were selected per AVA, so significant trends may emerge if more vineyard sites were included. While AVA was not significant, wines from one vineyard site were statistical outliers for guaiacol in certain years (Grubbs test; $p<0.0001$ ). The outlier vineyard site was not affected by smoke in any year studied but did experience berry dehydration, with subsequent high Brix, before it was harvested. There was also an $\sim 1.85-$ fold difference in both free and total guaiacol across all sites (Figure 2). Therefore, it is still important for wineries to understand the range of baseline values for their own vineyard sites.

Unlike free volatile phenols, the concentration of total volatile phenols either did not change due to vintage or did not increase in a consistent manner. Total guaiacol did not change much from 2016 to 2019 , but was significantly greater in 2015. This result was unexpected, but an extremely hot and dry growing season in 2015, combined with a relatively early harvest, may explain the increased concentrations of natural precursors.

The ratio of free to total guaiacol increased over time and appeared to approach a ratio of 1:2 (Figure 3). While this trend is in non-smoked wines, it may suggest that the worst-case scenario for smoke-tainted wine would be equal parts free and bound after five years. However, this trend needs further investigation.

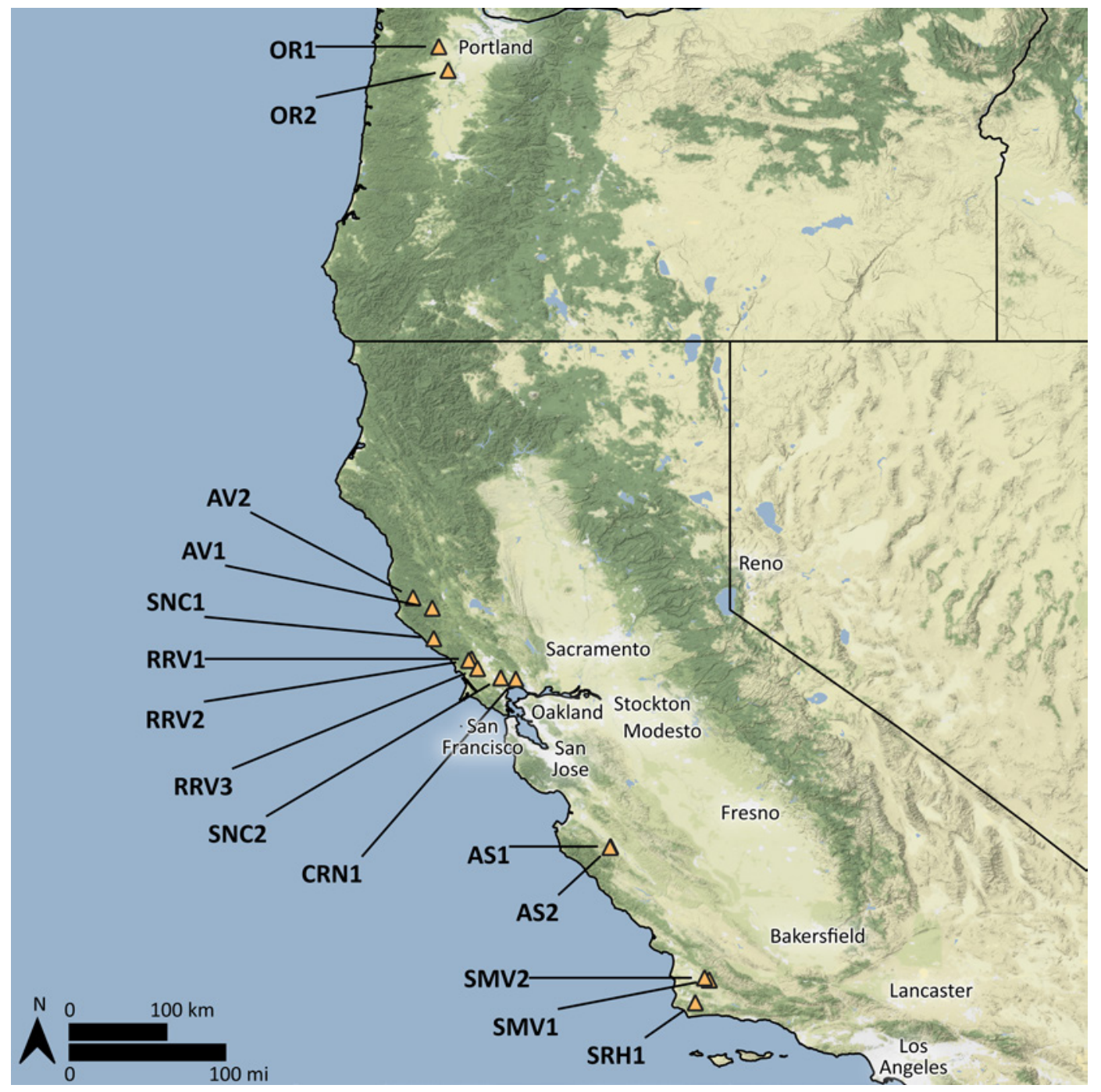

Figure 1 Fruit was harvested from 15 vineyard sites across California and Oregon over five years (2015 to 2019). Vineyard sites were within latitudes of $34^{\circ}$ and $45^{\circ}$ North and within longitudes of $120^{\circ}$ and $123^{\circ}$ West. 
In studies that report detectable levels of both guaiacol and 4-methylguaiacol, the calculated ratio between free guaiacol to free 4-methylguaiacol ranges from 3.7 to 4.5 in finished wines. ${ }^{3,13,17,18}$ However in one study, this ratio was up to 5.8 in wines just finishing primary fermentation. ${ }^{3}$ Wines in contact with oak tend to have higher concentrations of 4-methylguaiacol, depending on toast level, shifting this ratio down. ${ }^{19}$ Baseline wine samples studied here had guaiacol:4-methylguaiacol ratios of 4.1 to 26.9. The average ratio increased over time as free guaiacol increased faster than free 4-methylguaiacol (Table 2). The average ratio in 2019 wines was 6.0 \pm 0.3 . Because this ratio was greater than that observed in smoke-impacted wine, it may be a valuable parameter to monitor when determining whether results are due to baseline or smoke impact for a particular variety on a specific site.

\section{Broader Impact}

Smoke taint is a complex topic and years of research from across the world have helped further the industry's understanding of it. Significant progress has been made in identifying marker compounds, glycoconjugates, and vineyard conditions responsible for smoke impact. However, the wine industry still lacks practical techniques to determine whether a wine has been exposed to smoke and whether that exposure will lead to perceptible quality changes. Many times, winemakers must decide whether to harvest fruit or bottle wine without knowing the entire extent of smoke exposure. Becoming famil- iar with background levels of marker compounds allows winemakers to make more informed decisions.

This study examined baseline concentrations in Pinot noir clone 667 grown along the west coast of the United States. Baseline volatile phenol concentrations will likely change by varietal; past research has found that Syrah contained 20 to $40 \mu \mathrm{g} / \mathrm{L}$ free guaiacol. ${ }^{13}$ Other growing factors may also influence baseline concentrations, such as clone or farming practices such as vine water status. One vineyard site studied here was consistently an outlier, with high guaiacol concentrations over multiple years. In 2015, which was hot and dry, this site (RRV3) reached 30 Brix in August and experienced shrivel. While the fruit had a water addition prior to fermentation, adjusting for any shrivel concentration effects or increased alcohol extraction, the guaiacol concentration was still $23 \mu \mathrm{g} / \mathrm{L}$ at the time of analysis. This result suggests that growing conditions strongly affect baseline concentrations. Additionally, winemaking protocols may influence extraction from the berries. Because these factors are likely to be different for individual vineyards and wineries, it is important for each winery to test baseline concentrations in a subset of the wines produced.

Guaiacol and 4-methylguaiacol are the most common marker compounds examined during smoke analysis. They often show the greatest increase after smoke exposure and correlate strongly with sensory descriptors of smoke, burnt rubber, and leather. ${ }^{8,20}$ However, early smoke taint research established that neither guaiacol

Table 1 Average concentration of free and total acid hydrolysis volatiles over five vintages of Pinot noir wines. Data are presented as mean \pm standard error. Data not sharing a letter are significantly different at $p<0.05$ (Fisher's least significant difference), $\mathrm{n}=15$ in all years except 2018, when $\mathrm{n}=14$ due to potential smoke exposure at one site.

\begin{tabular}{|c|c|c|c|c|c|c|c|}
\hline \multirow[b]{2}{*}{ Vintage } & \multicolumn{7}{|c|}{ Free volatiles $(\mu \mathrm{g} / \mathrm{L}) /$ (detection limit) } \\
\hline & $\begin{array}{c}\text { Guaiacol } \\
(0.1)\end{array}$ & $\begin{array}{c}\text { 4-Methylguaiacol } \\
(0.1)\end{array}$ & $\begin{array}{c}\text { 4-Ethylguaiacol } \\
(1.0)\end{array}$ & $\begin{array}{c}\text { 4-Ethylphenol } \\
(1.0)\end{array}$ & $\begin{array}{c}m \text {-Cresol } \\
(0.5)\end{array}$ & $\begin{array}{c}\text { o-Cresol } \\
(0.5)\end{array}$ & $\begin{array}{c}p \text {-Cresol } \\
(5.0)\end{array}$ \\
\hline 2019 & $1.7 \pm 0.1 \mathrm{~d}$ & $0.29 \pm 0.01 b$ & $0.04 \pm 0.04$ & $0.30 \pm 0.02 c$ & $1.0 \pm 0.1$ & $1.8 \pm 0.1 b$ & $1.3 \pm 0.1 b$ \\
\hline 2018 & $2.6 \pm 0.2 \mathrm{~cd}$ & $0.30 \pm 0.02 b$ & $0.01 \pm 0.01$ & $0.50 \pm 0.06 b$ & $1.0 \pm 0.1$ & $1.8 \pm 0.1 b$ & $1.8 \pm 0.2 \mathrm{ab}$ \\
\hline 2017 & $4.1 \pm 0.3 b c$ & $0.40 \pm 0.03 \mathrm{a}$ & N.D. ${ }^{a}$ & $0.52 \pm 0.03 b$ & $1.1 \pm 0.1$ & $2.1 \pm 0.1 \mathrm{ab}$ & $1.8 \pm 0.3 a b$ \\
\hline 2016 & $4.6 \pm 0.5 c$ & $0.39 \pm 0.02 \mathrm{a}$ & $0.01 \pm 0.01$ & $0.80 \pm 0.07 a$ & $1.2 \pm 0.1$ & $2.4 \pm 0.2 \mathrm{a}$ & $2.2 \pm 0.3 \mathrm{a}$ \\
\hline \multirow[t]{2}{*}{2015} & $8.9 \pm 1.2 \mathrm{a}$ & $0.46 \pm 0.04 \mathrm{a}$ & $0.02 \pm 0.02$ & $0.85 \pm 0.07 \mathrm{a}$ & $1.2 \pm 0.1$ & $2.3 \pm 0.1 \mathrm{a}$ & $2.2 \pm 0.2 \mathrm{a}$ \\
\hline & \multicolumn{7}{|c|}{ Total (acid hydrolysis) volatiles $(\mu \mathrm{g} / \mathrm{L}) /$ (detection limit) } \\
\hline Vintage & $\begin{array}{c}\text { Guaiacol } \\
(0.1)\end{array}$ & $\begin{array}{c}\text { 4-Methylguaiacol } \\
(0.1)\end{array}$ & $\begin{array}{c}\text { 4-Ethylguaiacol } \\
(1.0)\end{array}$ & $\begin{array}{c}\text { 4-Ethylphenol } \\
(1.0)\end{array}$ & $\begin{array}{c}m \text {-Cresol } \\
(0.5)\end{array}$ & $\begin{array}{c}\text { o-Cresol } \\
(0.5)\end{array}$ & $\begin{array}{c}p \text {-Cresol } \\
(5.0)\end{array}$ \\
\hline 2019 & $8.9 \pm 0.4 \mathrm{~b}$ & $1.38 \pm 0.03 \mathrm{c}$ & $0.30 \pm 0.06 \mathrm{ab}$ & $2.3 \pm 0.1 \mathrm{c}$ & $\mathrm{N} / \mathrm{A}^{\mathrm{b}}$ & $3.6 \pm 0.2$ & $\mathrm{~N} / \mathrm{A}$ \\
\hline 2018 & $9.1 \pm 0.6 \mathrm{~b}$ & $1.49 \pm 0.04 \mathrm{bc}$ & $0.35 \pm 0.04 \mathrm{ab}$ & $3.2 \pm 0.2 \mathrm{a}$ & $\mathrm{N} / \mathrm{A}$ & $3.4 \pm 0.2$ & $\mathrm{~N} / \mathrm{A}$ \\
\hline 2017 & $9.9 \pm 0.8 b$ & $1.51 \pm 0.04 \mathrm{bc}$ & $0.24 \pm 0.04 \mathrm{bc}$ & $2.6 \pm 0.2 b$ & $\mathrm{~N} / \mathrm{A}$ & $3.6 \pm 0.2$ & $\mathrm{~N} / \mathrm{A}$ \\
\hline 2016 & $9.5 \pm 0.7 b$ & $1.59 \pm 0.07 b$ & $0.14 \pm 0.03 c$ & $2.1 \pm 0.1 \mathrm{c}$ & $\mathrm{N} / \mathrm{A}$ & $3.7 \pm 0.3$ & $\mathrm{~N} / \mathrm{A}$ \\
\hline 2015 & $17.3 \pm 1.5 \mathrm{a}$ & $1.81 \pm 0.11 \mathrm{a}$ & $0.37 \pm 0.04 \mathrm{a}$ & $3.1 \pm 0.1 \mathrm{a}$ & $\mathrm{N} / \mathrm{A}$ & $3.3 \pm 0.2$ & $\mathrm{~N} / \mathrm{A}$ \\
\hline
\end{tabular}

aN.D., compound not detected.

${ }^{b} \mathrm{~N} / \mathrm{A}$, compounds not measured after acid hydrolysis. 
nor 4-methylguaiacol were solely responsible for smoke taint aroma. ${ }^{17}$ Many winemakers are therefore familiar with guaiacol and 4-methylguaiacol concentrations when making inferences to smoke character. However, many commercial laboratories are now offering additional compounds such as $\mathrm{m}^{-}, o^{-}$, and $p$-cresol, which leads winemakers to question how to interpret these new results. Understanding the baseline of these additional compounds can help winemakers identify years when their concentrations spike.

Sensory thresholds for compounds commonly implicated in smoke exposure are of strong interest to winemakers. In 2012, best-estimate thresholds for guaiacol $(23 \mu \mathrm{g} / \mathrm{L}), m$-cresol $(20 \mu \mathrm{g} / \mathrm{L}), p$-cresol $(64 \mu \mathrm{g} / \mathrm{L})$, and $o$-cresol $(62 \mu \mathrm{g} / \mathrm{L})$ were published. ${ }^{8}$ However, during sensory analysis, wines were rated as smoke-exposed while having concentrations under these thresholds, which
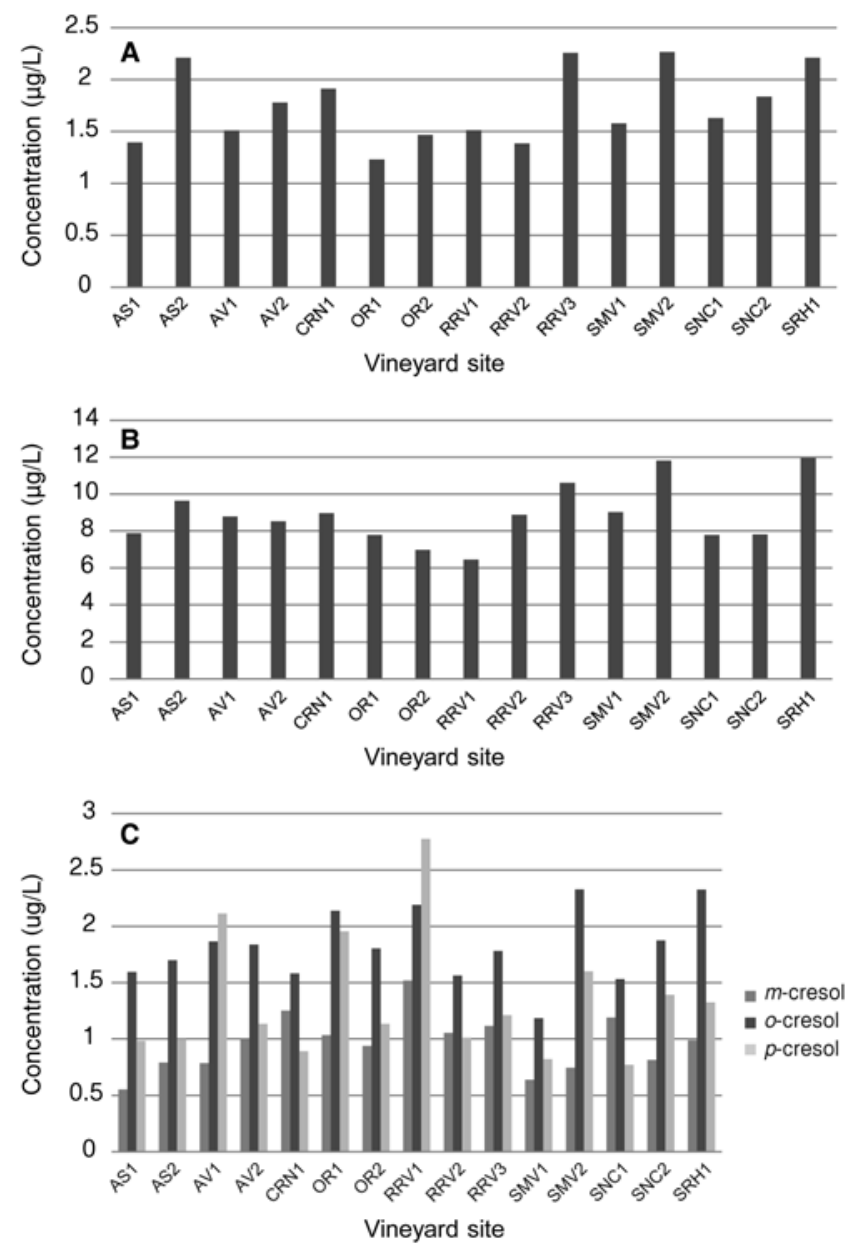

Figure 2 (A) Free and (B) total guaiacol, and (C) free cresol isomers from 2019 wines by vineyard site. Sites are labeled as American Viticultural Area and vineyard number (AS-Arroyo Seco; AV-Anderson Valley; CRN-Carneros; OR-Oregon; RRV-Russian River Valley; SMV-Santa Maria Valley; SNC-Sonoma Coast; SRH-Santa Rita Hills). pointed to either an additive or synergistic effect of these compounds or to smoke aroma contributions from additional, unidentified compounds. ${ }^{8}$ This unknown aspect to smoke impact sensory analysis has led commercial laboratories and other groups to make recommendations about smoke exposure at much lower concentrations of known smoke-related compounds than their reported thresholds, such as $4 \mu \mathrm{g} / \mathrm{L}$ guaiacol in whites and $6 \mu \mathrm{g} / \mathrm{L}$ in reds. ${ }^{13}$ As mentioned previously, the narrow range between baseline levels and potential smoke impact makes it difficult for winemakers to assess risk. However, once baseline concentration ranges for wines from a given region or vineyard and variety are known, risk can be assessed on the basis of increases over the historical baseline. This classification system for risk would eliminate some of the ambiguity winemakers face when interpreting results, especially in fire-damage years, and could potentially establish quality limits for discussions related to insurance claims or grower contracts.

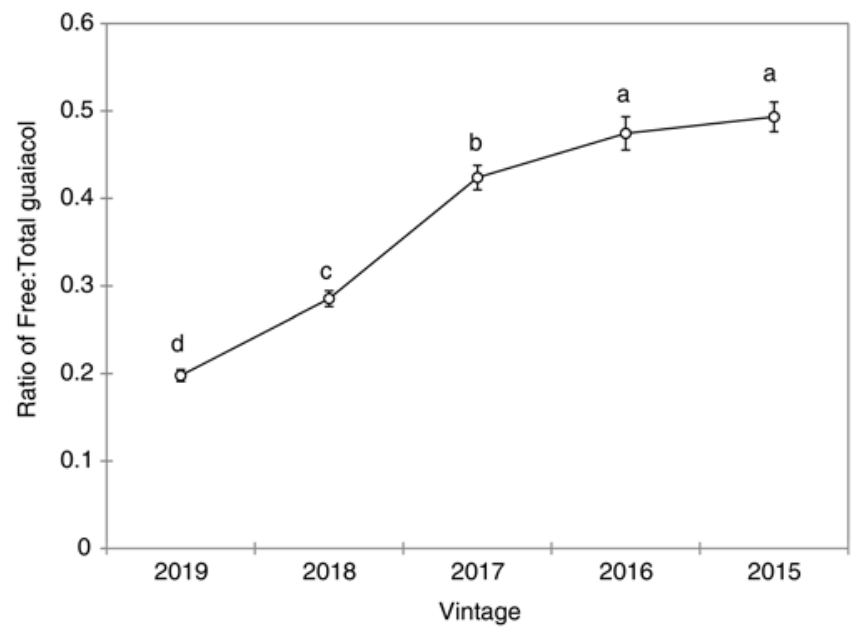

Figure 3 The ratio of free to total (acid hydrolysis-released) guaiacol increases with wine age. Data are presented as mean \pm standard error, significance established with Fisher's least significant difference; $p<0.05, \mathrm{n}=15$ in all years except 2018, where $\mathrm{n}=14$ due to potential smoke exposure at one site. Data not sharing a letter are significantly different at $p<0.05$ (Fisher's least significant difference).

Table 2 Ratio of guaiacol to 4-methylguaicol increased over time. Data are presented as mean \pm standard error. Data not sharing a letter are significantly different at $p<0.05$ (Fisher's least significant difference), $\mathrm{n}=15$ in all years except 2018, where $n=14$ due to potential smoke exposure at one site.

\begin{tabular}{cc}
\hline Vintage & Guaiacol:4-methylguaiacol \\
\hline 2019 & $6.0 \pm 0.3 \mathrm{~d}$ \\
2018 & $8.8 \pm 0.6 \mathrm{C}$ \\
2017 & $10.7 \pm 0.6 \mathrm{bc}$ \\
2016 & $11.8 \pm 0.8 \mathrm{~b}$ \\
2015 & $18.8 \pm 1.1 \mathrm{a}$ \\
\hline
\end{tabular}


Another way to reduce uncertainty regarding smoke volatile concentrations would be to find a marker compound that is not naturally present in grapes and only increases, even in small proportions, when smoke is present. This survey suggests that 4-ethylguaiacol may be a good candidate in Pinot noir because it is present at extremely low baseline concentrations (generally $<0.1$ $\mu \mathrm{g} / \mathrm{L}$ ) and there is very little bound fraction released by acid hydrolysis $(<0.5 \mu \mathrm{g} / \mathrm{L})$. However, preliminary research from the 2020 vintage indicates that accumulation of 4-ethylguaiacol was very low in smoke-impacted wines from California and Oregon (data not shown). Previous research found increased 4-ethylguaiacol concentrations in smoke-impacted wines and non-detectable levels in control wines, ${ }^{1,3,21}$ so further research will be important to establish a clear relationship. However, because 4-ethylguaiacol can also form from Brettanomyces metabolism in wines, the results should be interpreted carefully. Other possible smoke markers include the ratio between guaiacol and 4-methylguaiacol or the ratio between free and total guaiacol. However, these parameters would require more extensive research to establish a correlation with smoked or non-smoked wines.

An important consideration while assessing smoke risk during wine maturation is the release of bound compounds into their free forms over time. Acid hydrolysis is one technique to measure the glycoconjugate fraction of smoke phenolics. The method uses a combination of low $\mathrm{pH}$ and heat to release glycoconjugates to their free volatile phenol form. Because this method temporarily shifts the $\mathrm{pH}$ to 1.5, it likely overestimates the quantity of free smoke markers that will be released at wine $\mathrm{pH}$, because conditions in juice and wine are less extreme. Additionally, acid hydrolysis does introduce the risk of creating artifacts, as aglycones can rearrange at low $\mathrm{pH}^{22} \mathrm{Nev}-$ ertheless, it does give an estimate of total risk and the extent of smoke exposure. In this study, approximately half of the total (free and bound) guaiacol was in the free form after five years. Past research has seen a variable, but generally slow, rate of release of glycoconjugates over time depending on varietal and vintage. ${ }^{15}$ Additionally, previous research has only reported a maximum increase in free guaiacol of $6 \mu \mathrm{g} / \mathrm{L}$ over time, even when pools of glycoconjugates are much larger, suggesting the release of bound to free may be more stable than was observed in this study. ${ }^{11,15}$

\section{Experimental Design}

Winemaking. Winemaking followed the protocol by Grainger et al. ${ }^{23}$ Briefly, grape clusters produced by Vitis vinifera L. cv. Pinot noir clone Dijon 667 were harvested from 15 different vineyard sites. The sites represented eight different AVAs: Santa Rita Hills, Santa Maria Valley, Arroyo Seco, Carneros, Sonoma Coast, Russian River Valley, Anderson Valley, and Willamette Valley (OR).

Grapes were hand-harvested at $\sim 24$ Brix. The grapes were destemmed, but not crushed, into 200-L stainless steel fermentors containing $130 \mathrm{~L}$ must. Wines were fermented in quadruplicate at the University of California, Davis, Teaching and Research Winery. Must was chilled to $7^{\circ} \mathrm{C}$ for a three-day cold soak. Wine was warmed to $21^{\circ} \mathrm{C}$ prior to inoculation with RC212 (Lallemand), which had been rehydrated with SuperStart Rouge (Laffort) according to the manufacturer's recommendation. The must nitrogen was adjusted with a combination of NutriStart (Laffort) and diammonium phosphate (DAP) when the yeast assimilable nitrogen (YAN) was $<250 \mathrm{mg} / \mathrm{L}$. Nutristart was used to provide $35 \mathrm{~g}$ YAN/hL, with DAP used to supply the remaining difference. The fermentation temperature was held at $21^{\circ} \mathrm{C}$ for two days following inoculation, then allowed to rise to $27^{\circ} \mathrm{C}$ and maintained at this temperature for the remainder of fermentation. Automated pump-overs were used to maintain the temperature setpoint. Wines were pressed on the ninth day after destemming. Wines were cooled to $18^{\circ} \mathrm{C}$ and inoculated with $100 \mathrm{mg} / \mathrm{L} \mathrm{Lal-}$ vin VP41 malolactic bacteria (Lallemand). After malolactic fermentation was completed, fermentation replicates were blended, the wines were chilled to $13^{\circ} \mathrm{C}$, and potassium metabisulfite was added to adjust molecular $\mathrm{SO}_{2}$ to $0.6 \mathrm{mg} / \mathrm{L}$. Wines were bottled and sealed under screwcap closures approximately six months after harvest.

Wines were made during the 2015 to 2019 vintages following the above procedure. Chemical analysis was performed in February 2020, making the wines 0.5 to 4.5 years old at the time of analysis. Wines from the 2019 vintage were analyzed from keg samples, while wines from 2015 to 2018 were analyzed as bottle samples.

Sample preparation. Acid hydrolysis was used to release and measure all glycosylated volatile phenols and was performed according to Noestheden et al. ${ }^{24}$ Briefly, $14 \mathrm{~mL}$ wine was added to a $20 \mathrm{~mL}$ borosilicate glass vial. Guaiacol $\mathrm{d}_{3}$ was added as an extraction surrogate at a rate of $10 \mu \mathrm{g} / \mathrm{L}$. Hydrochloric acid $(\mathrm{HCl})$ was added until the $\mathrm{pH}$ reached 1.5. The wine was then heated to $100^{\circ} \mathrm{C}$ for four hours, then immediately chilled to room temperature. The wine was adjusted back to the original $\mathrm{pH}$ with $4 \mathrm{~N}$ sodium hydroxide $(\mathrm{NaOH})$ to make sample handling safer. Dilution from $\mathrm{HCl}$ and $\mathrm{NaOH}$ was accounted for in data analysis.

Gas chromatography tandem mass spectrometry (GC-MS/MS). A $10 \mathrm{~mL}$ sample of either wine or wine 
after acid hydrolysis was pipetted into a GC-MS vial. For free samples, both 4-methylguaiacol $d_{3}$ and guaiacol $d_{3}$ were added at a rate of $10 \mu \mathrm{g} / \mathrm{L}$ as internal standards. For acid hydrolysis samples, only 4-methylguaiacol $\mathrm{d}_{3}$ was added, as guaiacol $d_{3}$ was already used as a surrogate. Salt ( $2 \mathrm{~g}$ ) was then added to help force aromatic compounds into the headspace. Samples were mixed until the salt dissolved.

Solid-phase microextraction (SPME) (DVB/CAR/ PDMS; 50/30 $\mu \mathrm{m}, 23 \mathrm{Ga}$ ) sampling was used. While many researchers now use solid phase extraction and liquid injection, ${ }^{6}$ we chose to use SPME to more closely match protocols from commercial laboratories servicing the industry. The sample was incubated at $60^{\circ} \mathrm{C}$ for $3 \mathrm{~min}$ and then extracted for $30 \mathrm{~min}$ at $60^{\circ} \mathrm{C}$. Desorption time was $5 \mathrm{~min}$, and the inlet temperature was $250^{\circ} \mathrm{C}$. Injection was splitless. The GC column was TraceGOLD TG-WaxMS GC Column $(30 \mathrm{~m} \times 0.25 \mathrm{~mm}$ i.d. $\times 0.25 \mu \mathrm{m}$ film; Thermo Scientific). The carrier gas flow rate was $1.2 \mathrm{~mL} / \mathrm{min}$. Oven temperature started at $40^{\circ} \mathrm{C}$, was held at this temperature for $4 \mathrm{~min}$, increased to $100^{\circ} \mathrm{C}$ at $12^{\circ} \mathrm{C} / \mathrm{min}$, then increased to $160^{\circ} \mathrm{C}$ at $15^{\circ} \mathrm{C} / \mathrm{min}$, then increased to $250^{\circ} \mathrm{C}$ at $20^{\circ} \mathrm{C} / \mathrm{min}$ and held at this temperature for $8.5 \mathrm{~min}$.

Detection was carried out with selected reaction monitoring. The MS transfer line was held at $250^{\circ} \mathrm{C}$, and the ion source was held at $220^{\circ} \mathrm{C}$. Method validation was carried out and reproducibility was $<10 \%$ relative standard deviation (RSD) for all compounds in both wines and calibration standards for free volatile and acid hydrolysis. Guaiacol reproducibility was very robust: $2.5 \%$ RSD in standards and 5.5\% RSD in wines $(\mathrm{n}=6)$. Volatile phenol standards were purchased as a $1 \mathrm{~g} / \mathrm{L}$ mixture from Absolute Standards, Inc.

Statistical analysis. Data analysis was performed in XLSTAT. Analysis of variance was performed for vintage, AVA, and rootstock for each measured compound. Fisher's least significant difference was used to compare means. A two-sided Grubbs test for outliers was performed at $p<0.05$.

\section{References and Endnotes}

1. Kelly D, Zerihun A, Singh DP, Vitzthum von Eckstaedt C, Gibberd M, Grice K and Downey M. 2012. Exposure of grapes to smoke of vegetation with varying lignin composition and accretion of lignin derived putative smoke taint compounds in wine. Food Chem 135:787-798.

2. Krstic MP, Johnson DL and Herderich MJ. 2015. Review of smoke taint in wine: Smoke-derived volatile phenols and their glycosidic metabolites in grapes and vines as biomarkers for smoke exposure and their role in the sensory perception of smoke taint. Aust J Grape Wine Res 21:537-553.
3. Kennison KR, Gibberd MR, Pollnitz AP and Wilkinson KL. 2008. Smoke-derived taint in wine: The release of smokederived volatile phenols during fermentation of Merlot juice following grapevine exposure to smoke. J Agric Food Chem 56:7379-7383.

4. Korte F, Kvesitadze G, Ugrekhelidze D, Gordeziani M, Khatisashvili G, Buadze 0, Zaalishvili G and Coulston F. 2000. Organic toxicants and plants. Ecotoxicol Environ Saf 47:1-26.

5. Caffrey A, Lerno L, Rumbaugh A, Girardello R, Zweigenbaum J, Oberholster A and Ebeler SE. 2019. Changes in smoketaint volatile-phenol glycosides in wildfire smoke-exposed Cabernet Sauvignon grapes throughout winemaking. Am J Enol Vitic 70:373-381.

6. Noestheden M, Dennis EG, Romero-Montalvo E, DiLabio GA and Zandbery WF. 2018. Detailed characterization of glycosylated sensory-active volatile phenols in smoke-exposed grapes and wine. Food Chem 259:147-156.

7. Hjelmeland AK and Ebeler SE. 2015. Glycosidically bound volatile aroma compounds in grapes and wine: A review. Am J Enol Vitic 66:1-11.

8. Parker M et al. 2012. Contribution of several volatile phenols and their glycoconjugates to smoke-related sensory properties of red wine. J Agric Food Chem 60:2629-2637.

9. Mayr CM, Parker M, Baldock GA, Black CA, Pardon $\mathrm{KH}$ Williamson PO, Herderich MJ and Francis IL. 2014. Determination of the importance of in-mouth release of volatile phenol glycoconjugates to the flavor of smoke-tainted wines. J Agric Food Chem 62:2327-2336.

10. Singh DP, Chong HH, Pitt KM, Cleary M, Dokoozlian NK and Downey MO. 2011. Guaiacol and 4-methylguaiacol accumulate in wines made from smoke-affected fruit because of hydrolysis of their conjugates. Aust J Grape Wine Res 17:S13-S21.

11. Fudge AL, Ristic R, Wollan D and Wilkinson KL. 2011. Amelioration of smoke taint in wine by reverse osmosis and solid phase adsorption. Aust J Grape Wine Res 17:S41-S48.

12. Wilkinson KL et al. 2011. Comparison of methods for the analysis of smoke related phenols and their conjugates in grapes and wine. Aust J Grape Wine Res 17:S22-S28.

13. Herve E, Price S and Burns G. 2011. Free guaiacol and 4-methylguaiacol as markers of smoke taint in grapes and wines: Observations from the 2008 vintage in California. In Oeno 2011: Proceedings of the 9th Symposium International d'CEnologie, Bordeaux, France.

14. López R, Ezpeleta E, Sánchez I, Cacho J and Ferreira V. 2004. Analysis of the aroma intensities of volatile compounds released from mild acid hydrolysates of odourless precursors extracted from Tempranillo and Grenache grapes using gas chromatography-olfactometry. Food Chem 88:95-103.

15. Ristic R, van der Hulst L, Capone DL and Wilkinson KL. 2017. Impact of bottle aging on smoke-tainted wines from different grape cultivars. J Agric Food Chem 65:4146-4152.

16. Parker M, Baldock G, Hayasaka Y, Mayr C, Williamson P, Francis IL, Krstic M, Herderich M and Johnson D. 2013. Seeing through smoke. Wine Vitic J 28:42-46. 
17. Kennison KR, Wilkinson KL, Williams HG, Smith JH and Gibberd MR. 2007. Smoke-derived taint in wine: Effect of postharvest smoke exposure of grapes on the chemical composition and sensory characteristics of wine. J Agric Food Chem 55:10897-10901.

18. Kennison KR, Wilkinson KL, Pollnitz AP, Williams HG and Gibberd MR. 2009. Effect of timing and duration of grapevine exposure to smoke on the composition and sensory properties of wine. Aust J Grape Wine Res 15:228-237.

19. Campbell JI, Skyes M, Sefton MA and Pollnitz AP. 2005. The effects of size, temperature and air contact on the outcome of heating oak fragments. Aust J Grape Wine Res 11:348-354.

20. Kennison KR, Wilkinson KL, Pollnitz AP, Williams HG and Gibberd MR. 2011. Effect of smoke application to field-grown Merlot grapevines at key phenological growth stages on wine sensory and chemical properties. Aust J Grape Wine Res 17:S5-S12.
21. Kennison KR, Wilkinson KL, Pollnitz AP, Williams HG and Gibberd MR. 2009. Effect of timing and duration of grapevine exposure to smoke on the composition and sensory properties of wine. Aust J Grape Wine Res 15:228-237.

22. Hjelmeland AK and Ebeler SE. 2015. Glycosidically bound volatile aroma compounds in grapes and wine: A review. Am J Enol Vitic 66:1-11.

23. Grainger C, Yeh A, Byer S, Hjelmeland A, Lima MMM and Runnebaum RC. 2021. Vineyard site impact on the elemental composition of Pinot noir wines. Food Chem 334:127386.

24. Noestheden M, Thiessen K, Dennis EG, Tiet B and Zandberg WF. 2017. Quantitating organoleptic volatile phenols in smoke-exposed Vitis vinifera berries. J Agric Food Chem 65:8418-8425. 